\title{
Optimization of Mine Development Scheme Based on Empowerment Combination TOPSIS
}

\author{
DENG Hongwei, LUO Liming, ZHANG Jian
}

School of Resources and Safety Engineering, Central South University, Changsha 410083, Hunan, China

Keywords: entropy weigh; analytic hierarchy process (AHP) ; Technique for order Preference by Similarity to ideal Solution (TOPSIS); development scheme; index system; Synthetic superior degrees

\begin{abstract}
The optimization of mine development Scheme is one of the technical problems in the design of underground mining. With all influencing factors, such as economy, technology, safety, and time considered, a comprehensive evaluation index system of mine development scheme was established by Delphi method to solve the drawback of traditional development Scheme selection. The weights of each index was determined by entropy method and analytic hierarchy process (AHP), then using the technique for order preference by similarity to ideal solution(TOPSIS) based on empowerment combination to evaluate the development scheme, and calculating the synthetic superior degrees of each development scheme, realized the optimization of mine development scheme. Taking the example of a mine in Yunnan Province, the synthetic superior degrees of the three development scheme evaluated by the TOPSIS method based on empowerment combination were $0.98863,0.00931$ and 0.50053 , respectively, with the first method i.e., decline development combination with inclined shaft, being the best. The research results show that, the optimization of mine development scheme based on empowerment combination TOPSIS is more reliable.
\end{abstract}

\section{Introduction}

In the design of underground mining, mine development scheme selection is one of the problems we must face, it is seriously important to the overall design of a mine, and it is also a complex system decision making process. The superior and inferior of mine development scheme selection has a direct impact on mine production and economic. Traditional mine development scheme selection is based on the advantages and disadvantages of each scheme and simple technical and economic comparison, the process of selection has great one-sidedness and subjectivity, so the result of selection may be affected by personal experience and preferences easily and cannot reflect the actual situation of mine correctly. In recent years, with the emergence of a series of mathematical optimization method, lots of scholars ${ }^{[1 \sim 2]}$ in the domestic and overseas study on the selection of mine development scheme, which promoted the decision-making process of the mine development scheme selection.

The decision-making process of mathematical optimization method are all involved in the determination of weight value, the accuracy of the index weights directly determines whether there is a good evaluation result or not. At present, two categories method, subjective empower and objective empower, are used to determine the index weight. The method of subjective empower which is get the index weight by experts' personal preferences and experience judgment, so the optimization result has certain subjective randomness, such as analytic hierarchy process(AHP), putting preference ratio method and Delphi method ${ }^{[3 \sim 4]}$. Objective empower method is based on the inherent regular in the original data for mathematical reasoning to determine the weight, it has strong mathematical theory basis and avoid the subjectivity of the index weight calculation effectively, but sometimes it may deviate with the actual importance of every index, and it has a poor explanatory, such as entropy method, principal component analysis (PCA) and the maximum deviation method. In view of this, this paper use the entropy weight method combined with analytic 
hierarchy process (AHP) empowerment combination to determine index weight, considering the experience judgment of expert and make full use of the inherent regular in the original data. Using the technique for order preference by similarity to ideal solution (TOPSIS) based on empowerment combination to evaluate the development scheme, realized the Optimization of mine development scheme, provide a new way for the optimization of mine development scheme.

\section{The establishment of a comprehensive evaluation index system of the mine development scheme}

The selection of mine development scheme is a complicated system engineering, it Should not only consider the geological occurrence characteristics and mining technological conditions of ore body itself, but also should consider many other factors. With all influencing factors, such as economy, technology, safety, and time considered, a comprehensive evaluation index system of mine development scheme was established by Delphi method in this paper. The specific evaluation index are as follows: Firstly is economic index $(E)$, including construction $\operatorname{cost}\left(K_{1}\right)$, operation $\operatorname{cost}\left(K_{2}\right)$; Secondly is the technical index $(F)$, including development reserve $\left(K_{3}\right)$, transport work $\left(K_{4}\right)$ and Stocked ore of safety pillar $\left(K_{5}\right)$; Thirdly is the safety index $(G)$, including ventilation conditions $\left(K_{6}\right)$ and construction safety $\left(K_{7}\right)$; Fourthly is time index $(H)$, including the construction time $\left(K_{8}\right)$. Comprehensive evaluation index system of the mine development scheme is shown in figure. 1.

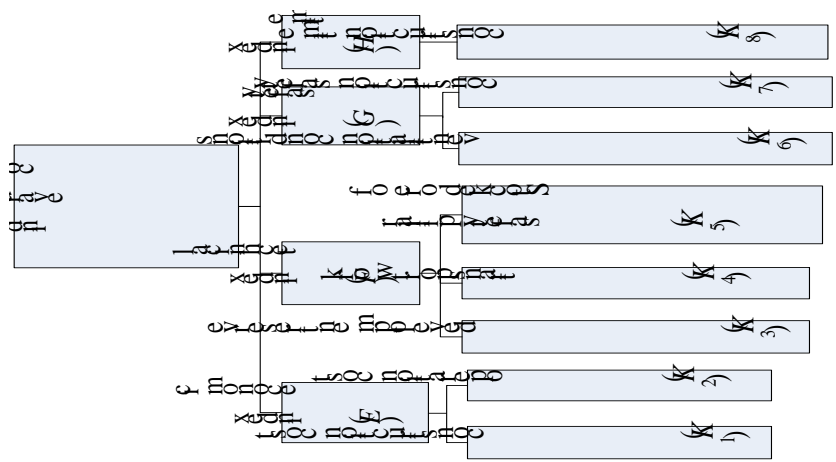

Fig. 1 Comprehensive evaluation indexes system of mine development scheme

\section{Calculate the weight of every index}

\subsection{Confirm the objective weights of every index by entropy weight method}

The information entropy is a measurement of the uncertainty of the system ${ }^{[5]}$, it is the amount of variation in the information system. The smaller the amount of information, the greater the degree of variation, the greater the entropy value; Conversely, the greater the amount of information, the smaller the degree of variation, the smaller the entropy value ${ }^{[6 \sim 7]}$. The steps of entropy weight method to calculate the index weight are as follows ${ }^{[8 \sim 9]}$ :

(1) Standardization of original data matrix

Generally the indexes have different dimensions, for which they can't be compared directly. So the index values in matrix X must be standard ${ }^{[10 \sim 11]}$. There are many ways on standardization. A common way is showed as:

$$
y_{i j}=x_{i j} / \sum_{i=1}^{m} x_{i j}
$$

(2) Calculate information entropy

$$
S\left(y_{j}\right)=-\sum_{i=1}^{m} y_{i j} \ln y_{i j}
$$

(3) Calculate the entropy

$$
S_{j}=S\left(y_{i}\right) / \ln m
$$

(4) Calculate difference degree of every index 
(5) Calculate the entropy weight

$$
G_{j}=1-S_{j}
$$

$$
a_{j}=G_{j} / \sum_{j=1}^{n} G_{j}
$$

\subsection{Confirm the subjective weights of every index by analytic hierarchy process}

The way of analytic hierarchy process (AHP) to get a judgment matrix is based on comparing relative importance degree of each index, then Calculate the maximum eigenvalue of the matrix, Its corresponding eigenvector is the weight of evaluation index. The steps of AHP to obtain the index weight are as follows:

(1) Construct judgment matrix

Via compare relative importance degree of each index, obtain judgment matrix $D_{i j}$, $D_{i j}$ show the importance degree of $D_{i}$ relative to the index $D_{j}$, and $D_{i j}$ times $D_{j i}$ is equal to one. The value of judgment matrix put forward based on Satty 1-9 scaling method.

(2) Calculate the weight of evaluation index.

According to the judgment matrix $D_{i j}$, solve the equation $D_{i j} b=r_{\max } b$, obtain the maximum eigenvalue of the Matrix, Its corresponding eigenvector $b$ is the weight of evaluation index.

(3) Consistency check

Due to the degree of the importance of each index is decided by the expert, which was empirical and random, in order to confirm the rationality of weight distribution, consistency check is necessary to the judgment matrix. When the index value is less than 0.1 , we define that the judgment matrix meets the requirements, otherwise, the judgment matrix needs to be constructed anew until it meets the consistency check requirements.

\subsection{Confirm the weights of every index by Empowerment Combination}

Because of the analytic hierarchy process (AHP) relies too much on personal experience judgment, while entropy weight method is overemphasis on mathematical reasoning, the weight of index is often deviate from the actual. Reasonable methods of empowerment should consider both the expert's experience and make full use of the inherent regular in index data, so the idea of empowerment combination was brought in this paper, multiply subjective weights of every index by objective weights, and deal with the degree of quantitative, thus, magnify the importance of each index and improve the resolution of index weight. The weights of every index by empowerment combination are showed as:

$$
\mathrm{c}_{j}=\frac{a_{j} \times b_{j}}{\sum_{j=1}^{n}\left(a_{j} \times b_{j}\right)}
$$

\section{4 the TOPSIS Method Based on Empowerment Combination}

Technique for order Preference by Similarity to ideal Solution(TOPSIS) is a kind of statistic analysis method, which sorts the evaluated objects by "Ideal Solution” and “Minus Ideal Solution” of multi-attribute decision-making. The ideal solution is a virtual optimal solution, in which every index gets the optimal value. Whereas minus ideal solution is the virtual worst solution, in which every index gets the worst value ${ }^{[12 \sim 13]}$. The comprehensive assessment process of TOPSIS based on empowerment combination is showed as follow:

(1) Establish decision-making data matrix

Suppose there are $m$ evaluated objects and $n$ evaluated indexes. The indexes values of all the evaluated objects compose of the matrix $X$, in which $x_{i j}$ means the value of the index No. $j$ of the evaluated object No. $i$. The decision-making data matrix is showed as: 
(2) Standardization of original data matrix

$$
X=\left[\begin{array}{cccc}
x_{11} & x_{12} & \cdots & x_{1 n} \\
x_{21} & x_{22} & \cdots & x_{2 n} \\
\vdots & \vdots & \vdots & \vdots \\
x_{m 1} & x_{m 2} & \cdots & x_{m n}
\end{array}\right]
$$

$$
y_{i j}=x_{i j} / \sum_{i=1}^{m} x_{i j}
$$

(3) Construct Standardized Weighted Matrix

$$
V=\left(v_{i j}\right)_{m \times n}=\left[\begin{array}{cccc}
c_{1} y_{11} & c_{2} y_{12} & \cdots & c_{n} y_{1 n} \\
c_{1} y_{21} & c_{2} y_{22} & \cdots & c_{n} y_{2 n} \\
\vdots & \vdots & \vdots & \vdots \\
c_{1} y_{m 1} & c_{2} y_{m 2} & \cdots & c_{n} y_{m n}
\end{array}\right]
$$

(4) Confirm the Ideal Solution and the Minus Ideal Solution

$$
\begin{gathered}
V^{-}=\left\{\left(\min _{i} v_{i j} \mid j \in J_{1}\right),\left(\max _{i} v_{i j} \mid j \in J_{2}\right) \mid i=1,2, \ldots, \mathrm{m}\right\} \\
V^{+}=\left\{\left(\max _{i} v_{i j} \mid j \in J_{1}\right),\left(\min _{i} v_{i j} \mid j \in J_{2}\right) \mid i=1,2, \ldots, \mathrm{m}\right\}
\end{gathered}
$$

In which, $V$-Minus Ideal Solution; $V^{+}$-Ideal Solution

$J_{1}$-index set on benefit; $J_{2}$-index set on cost.

(5) Calculate Distance

The distances of ideal solutions and minus ideal solutions are showed separately as:

$$
\begin{aligned}
& d_{i}^{+}=\left[\sum_{j=1}^{n}\left(v_{i j}-v_{j}^{+}\right)^{2}\right]^{1 / 2} \\
& d_{i}^{-}=\left[\sum_{j=1}^{n}\left(v_{i j}-v_{j}^{-}\right)^{2}\right]^{1 / 2}
\end{aligned}
$$

(6) Calculate synthetic superior degrees

Synthetic superior degrees of each alternative development scheme are showed as:

$$
C_{i}=d_{i}^{-} /\left(d_{i}^{+}+d_{i}^{-}\right), \mathrm{i}=1,2, \ldots, \mathrm{m} 。
$$

\section{Engineering example}

\subsection{Engineering situation}

As one of subordinate company of YunnanTin Corporation, LaoChang Tin mine, which with good continuity and large scale, mainly occurs around the granite depression zones. It can be divided into eight ore body, i.e., 13-8-1、13-8-2、13-8-3、13-8-4、13-8-5、13-8-6、13-8-7and 13-8-8. The thickness of stone between each layer is small, some of which even less than $10 \mathrm{~m}$. the trend of ore body is south east and its dip $0 \sim 19^{\circ}$, average $10^{\circ}$. The length of exploration control ore body is $100 \sim 550 \mathrm{~m}$, and the width is $35 \sim 321 \mathrm{~m}$, the Max thickness of Ore body is $21.9 \mathrm{~m}$, the average thickness of each layer Ore body is $2.5 \sim 11.56 \mathrm{~m}$, it is a typical gentle dip multi-layer ores of medium size.

\subsection{Preliminary selection of development scheme}

According to the ore-body reserves, engineering geological conditions, mining technical conditions and the existing scheme layout of old factory in Yunnan, Three development schemes were selected, which are economically rational and technically feasible. There are development method with ramp and inclined shaft $\left(A_{1}\right)$, development method with double ramp $\left(A_{2}\right)$ and development method with ramp and adit $\left(A_{3}\right)$, respectively. The original data are shown in table 1 . 
Table 1 The index of mine development project

\begin{tabular}{|c|c|c|c|c|c|c|c|c|}
\hline \multirow{2}{*}{ scheme } & \multicolumn{2}{|c|}{$E$} & \multicolumn{3}{|c|}{$F$} & \multicolumn{2}{|c|}{$G$} & $H$ \\
\hline & $K_{1}$ & $K_{2}$ & $K_{3}$ & $K_{4}$ & $K_{5}$ & $K_{6}$ & $K_{7}$ & $K_{8}$ \\
\hline$A_{1}$ & 4035.6 & 7726.7 & 143125 & 11025 & 3195 & 0.85 & 0.85 & 105 \\
\hline$A_{2}$ & 3909.2 & 7693.5 & 145590 & 11630 & 3254 & 0.8 & 0.8 & 125 \\
\hline$A_{3}$ & 3853.2 & 7767.2 & 144676 & 11177 & 3120 & 0.85 & 0.9 & 115 \\
\hline
\end{tabular}

Note: the ventilation conditions and the construction security is based on the actual situation, the score was obtained by experts in $[0,1]$, the ventilation conditions and construction safety is better while the value is greater.

\subsection{Comprehensive evaluation of the schemes}

According to formula (1), the standardized matrix can be constructed as:

$$
Y=\left[\begin{array}{llllllll}
0.34206 & 0.33323 & 0.33024 & 0.32588 & 0.33389 & 0.34000 & 0.33333 & 0.30435 \\
0.33134 & 0.33180 & 0.33593 & 0.34376 & 0.34006 & 0.32000 & 0.31373 & 0.36232 \\
0.32660 & 0.33497 & 0.33383 & 0.33036 & 0.32605 & 0.34000 & 0.35294 & 0.33333
\end{array}\right]
$$

According to formula (2)-formula (6), the empowerment combination of every index can be calculated as:

$$
\mathrm{C}=\left[\begin{array}{llllllll}
0.01053 & 0.00025 & 0.00318 & 0.05217 & 0.01244 & 0.04884 & 0.02709 & 0.84549
\end{array}\right]
$$

According to formula (10)-formula (11), confirm the ideal solution and the minus Ideal Solution $\left\{\mathrm{V}^{+}=\left[\begin{array}{llllllll}0.01302 & 0.00054 & 0.00174 & 0.01790 & 0.01025 & 0.02909 & 0.08653 & 0.16317\end{array}\right]\right.$

$$
\left\{\mathrm{V}^{-}=\left[\begin{array}{lllllllll}
0.01364 & 0.00055 & 0.00177 & 0.01889 & 0.01069 & 0.02738 & 0.07692 & 0.19425
\end{array}\right]\right.
$$

According to formula (12)-formula (13), calculate the distance between every evaluated scheme and the ideal solution respectively:

$$
\left\{\begin{array} { l } 
{ d _ { 1 } ^ { + } = 0 . 0 0 0 5 6 } \\
{ d _ { 1 } ^ { - } = 0 . 0 4 9 0 4 }
\end{array} \quad \left\{\begin{array} { l } 
{ d _ { 2 } ^ { + } = 0 . 0 4 9 0 4 } \\
{ d _ { 2 } ^ { - } = 0 . 0 0 0 1 1 }
\end{array} \quad \left\{\begin{array}{l}
d_{3}^{+}=0.02451 \\
d_{3}^{-}=0.02456
\end{array}\right.\right.\right.
$$

According to formula (14), calculate the Synthetic superior degrees of each alternative development scheme respectively:

\subsection{Results analysis}

$$
C=\left[\begin{array}{lll}
0.98863 & 0.00931 & 0.50053
\end{array}\right]
$$

According to the results of comprehensive evaluation, the synthetic superior degrees of the three development scheme were $0.98863,0.00931$ and 0.50053 , respectively. Obviously, $A_{1}>A_{3}>A_{2}$, i.e., development method with ramp and inclined shaft is the best scheme.

In order to compare the superior and inferior of different method of empowerment. The TOPSIS method based on entropy weight and the TOPSIS method based on AHP was used to evaluate the three development schemes, the synthetic superior degrees of the three development scheme were $0.86655,0.01293,0.54189$ and $0.94392,0.02966,0.51848$, respectively. The evaluation results, which both are $A_{1}>A_{3}>A_{2}$, are the same as empowerment combination TOPSIS. The synthetic superiority degree of three kinds of empowerment methods are showed as Figure 2. Figure 2 shows that the results of empowerment combination TOPSIS has the largest degree of differentiation, and its evaluation results are more stable and reasonable. 


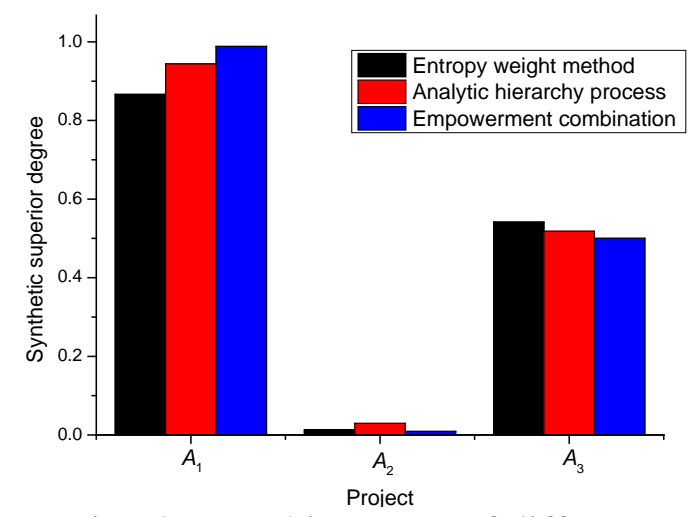

Fig. 2 The synthetic superior degrees histogram of different method of empowerment

\section{Conclusions}

(1) A comprehensive evaluation index system, which contains eight comprehensive evaluation indexes, is established by Delphi method. weights of each index were determined by entropy method and analytic hierarchy process (AHP), with subjective weights and objective weights considered synthetically, the expert's experience and the inherent regular in index data were also taken into account, which avoid deviating which caused by the single weight effectively.

(2) Using the technique for order preference by similarity to ideal solution (TOPSIS) based on empowerment combination to evaluate the three development schemes of a mine in Yunnan Province. the synthetic superior degrees of the three development scheme were $0.98863,0.00931$ and 0.50053 , respectively, in other words, the first scheme, i.e., development method with ramp and inclined shaft, is the best.

(3) By comparing three methods of empowerment, i.e., empowerment combination, analytic hierarchy process (AHP) empowerment, entropy weight method empowerment, the results show: evaluation results of three methods are consistent, but the method choice based on empowerment combination TOPSIS has higher resolution and more stable. It shows that the method which is used for optimization of mine development scheme is feasible and reliable, its calculation process is simple and its analysis result is reasonable. Optimization of mine development scheme based on empowerment combination TOPSIS is a beneficial attempt.

\section{References}

[1] Qin Jie. Evaluation on Mine Development project Based on AHP[J]. Coal mining Technology, 2012, 17 (1):37-41. (In Chinese)

[2] Wang Qi, Zhang Jianhua, Liu Jun, et al. Development Scheme Optimization Selection Based on the Analytic Hierarchy Process Method and Grey Correlation Analysis Method[J]. Modern Mining, 2014 (4):15-19. (In Chinese)

[3] Xia Ping, Wu Darong, Huang Xueying, et al. Delphi research on the evaluation indicators system for clinical pathway management[J]. Chinese Journal of Hospital Administration, 2012, 28(11):811-817. (In Chinese)

[4] Chen Yuanjiang, Yin Jin. Optimization of Mining Method Based on AHP-TOPSIS[J]. Science \& Technology Review, 2013, 31(7):57-60. (In Chinese)

[5] Lv Pan, Qiao Yi, Ge Liting. Comprehensive decision-making of transmission network planning based on entropy TOPSIS[J]. Journal of North China Electric Power University,2010,37(4):24-28. (In Chinese)

[6] Yang Yuzhong, Zhang Qiang, Wu Liyun. Technique for Order Preference by Similarity to Ideal Solution Based on entropy Weight for Supplier Selection[J]. Transactions of Beijing Institute of 
Technology, 2006,26(1):990-996. (In Chinese)

[7] Yin Liping, Liu Jinhai, Zhu Zhuohui. Mining Method Based on Technique for Order Preference by Similarity to Ideal Solution[J]. Mining and Metallurgical Engineering,2010,30(3):12-15. (In Chinese)

[8] Kang Zhiqiang, Zhou Hui, Feng Xiating, et al. Extenics Theory Evaluation of Underground Tunnel Rock Quality[J]. Chinese Journal of Underground Space and Engineering, 2008, 4(2):259-264. (In Chinese)

[9] Ou Yangsen, Shi Yili. A New Improved Entropy Method and Its Application in Power Quality Evaluation[J]. Automation of Electric Power Systems, 2013,37(21):156-159. (In Chinese)

[10] Du Kun, Li Xibing, Zhou Jian, et al. Application of Fuzzy Matter. element Model Based on Coefficients of Entropy in Optimization of Mining Scheme[J]. Mining and Metallurgical Engineering, 2010, 30(5):12-17. (In Chinese)

[11] Chu Xiaojie, Yan Huifeng, Zhou Renjun, et al. Application of entropy coefficient based attribute recognition model in comprehensive evaluation for grid company[J]. Journal of Electric Power science and Technology, 2007, 22(4):56-59. (In Chinese)

[12] Dagdeviren M, Yavuz S, Kilinc N. Weapon selection using AHP and TOPSIS methods under fuzzy environment[j].Expert Systems with Application, 2009,36(4):8143-8151. (in English)

[13] Lin M C, Wang C C, Chen M S, et al. Using AHP and TOPSIS approaches in customer-driven product design process[J].Computer in Industry, 2008,59(1):17-31. (in English) 